\title{
Controle do caruncho-do-feijoeiro Zabrotes subfasciatus com óleos vegetais, munha, materiais inertes e malathion ${ }^{(1)}$
}

\author{
Flávia Rabelo Barbosa(2), Massaru Yokoyama(3), Pedro Antônio Arraes Pereira ${ }^{(3)}$ \\ e Francisco José Pfeilsticker Zimmermann ${ }^{(3)}$
}

\begin{abstract}
Resumo - Na busca de alternativas ao controle químico do caruncho Zabrotes subfasciatus (Coleoptera:Bruchidae), avaliou-se, em feijoeiro (Phaseolus vulgaris L.), o efeito de três genótipos, cv. Carioca e duas linhagens contendo a proteína arcelina (Arc1 e Arc3), e da adição nos grãos armazenados de óleo de soja (Glycine max Merrill); óleo de nim (Azadirachta indica A. Juss.), munha (resíduo de trilha da colheita), calcário dolomítico e terra de formigueiro, comparativamente aos grãos não tratados e ao controle químico com malathion $500 \mathrm{CE}$. O experimento foi realizado no laboratório da Embrapa-Centro Nacional de Pesquisa de Arroz e Feijão, localizado no Município de Santo Antônio de Goiás, GO, em condições não controladas. Na linhagem Arc1, constatou-se maior proteção aos danos do caruncho, observando-se redução do número de ovos e de adultos emergidos e da porcentagem de sementes danificadas em relação à Arc3 e à cv. Carioca. Quando os grãos foram tratados com malathion, óleo de nim e óleo de soja, observou-se menor número de ovos e de adultos emergidos e redução de danos, e não houve diferença na porcentagem de sementes danificadas entre o malathion e o óleo de nim. A mistura das sementes com terra de formigueiro conferiu baixa proteção ao caruncho, enquanto os tratamentos com munha e calcário dolomítico não apresentaram eficiência na redução da progênie e dos danos de Z. subfasciatus.
\end{abstract}

Termos para indexação: Phaseolus vulgaris, controle de pragas, resistência aos pesticidas.

\section{Control of the Mexican bean weevil Zabrotes subfasciatus with vegetable oils, trashing residues, inert materials and malathion}

\begin{abstract}
The effects of malathion 500 CE, neem (Azadirachta indica A. Juss.) and soybean (Glycine max Merrill) oils, inert materials and trashing residues on the control of Zabrotes subfasciatus (Coleoptera:Bruchidae) were evaluated on bean seeds (Phaseolus vulgaris L.), using the cultivar Carioca and two lines containing the protein arcelin (Arc1 and Arc3). The experiment was carried in a laboratory at Embrapa-Centro Nacional de Pesquisa de Arroz e Feijão, Santo Antônio de Goiás, GO, Brazil, under noncontrolled conditions. The highest levels of protection against $Z$. subfasciatus were observed in Arc1, with reduction in the number of eggs, number of emerged adults and percentage of damaged seeds than in Arc 3 and Carioca cultivar. The number of eggs, number of emerged adults and the percentage of damaged seeds were reduced when the seeds were treated with malathion, neem and soybean oils. There was not difference in percentage of damaged seeds between malathion and neem oil. The treatment of the seeds using ant hill ground showed low efficiency, and trashing residues and dolomitic lime did not show reduction on the progeny and damage of $Z$. subfasciatus.
\end{abstract}

Index terms: Phaseolus vulgaris, pest control, pesticide resistance.

(1) Aceito para publicação em 18 de dezembro de 2001.

(2) Embrapa-Centro de Pesquisa Agropecuária do Trópico Semi-Árido, Caixa Postal 23, CEP 56300-970 Petrolina, PE. E-mail: flavia@cpatsa.embrapa.br

(3) Embrapa-Centro Nacional de Pesquisa de Arroz e Feijão, Caixa Postal 179, CEP 74001-970 Santo Antônio de Goiás, GO. E-mail: massuru@cnpaf.embrapa.br, arraes@cnpaf.embrapa.br, fjpz@cnpaf.embrapa.br

\section{Introdução}

O caruncho Zabrotes subfasciatus (Boheman) (Coleoptera:Bruchidae) é considerado uma das principais pragas do feijão armazenado; distribui-se nas Américas Central e do Sul, África, na região Mediterrânea e na Índia. Seus danos são decorrentes da pe- 
netração e alimentação das larvas no interior dos grãos, provocando perda de peso, redução do valor nutritivo e do grau de higiene do produto, pela presença de excrementos, ovos e insetos. Além disso, o poder germinativo das sementes pode ser reduzido ou totalmente perdido (Toledo \& Marcos Filho, 1977; Gallo et al., 1988).

O controle químico tem sido eficaz no controle dos carunchos, porém, sua utilização é dificultada pelo custo dos produtos e por problemas de toxicidade decorrentes da utilização dos inseticidas. Para substituir o tratamento químico, pequenos produtores têm utilizado várias práticas, como: mistura dos grãos de feijão com areia, cal, cinza de madeira, resíduos de trilha da colheita (munha), terra de formigueiro, pimenta-do-reino ou óleos (Gutierrez \& Schoonhoven, 1981; Don-Pedro, 1989).

Barreto et al. (1983) observaram que houve interferência na biologia de Acanthoscelides obtectus (Coleoptera:Bruchidae) e redução de sua população, quando grãos de caupi (Vigna unguiculata Walp.) foram misturados com calcário. De acordo com Mordue \& Nisbet (2000), o óleo de sementes de nim (Azadirachta indica A. Juss.) contém azadiractina e outros compostos potencialmente bioativos, sendo eficiente no controle de pragas de grãos armazenados. Seu efeito repelente sobre Z $Z$. subfasciatus foi comprovado por Oliveira \& Vendramim (1999). Hall \& Harman (1991) constataram que o tratamento de sementes armazenadas de Phaseolus vulgaris com óleo de soja (Glycine max Merrill) resultou em redução da oviposição, da emergência de adultos e dos danos de Z. subfasciatus. Observaram, ainda, que a utilização do óleo não alterou a germinação, nem a viabilidade das sementes. Acredita-se que o efeito de óleos adicionados às sementes é devido ao bloqueio do oxigênio para a respiração dos insetos e ao efeito inseticida de alguns de seus componentes, principalmente triglicerídeos (Uvah \& Ishaya, 1992). Quanto ao uso de materiais, como areia, cinza, terra de formigueiro e outros, as informações são, na maior parte, de natureza empírica, necessitando de estudos mais acurados antes de sua recomendação (Guedes, 1991).

A busca de cultivares com resistência aos carunchos tem sido realizada em diversos programas de melhoramento genético do feijoeiro. Em avaliações de milhares de acessos de feijão cultivado, não foram encontrados níveis satisfatórios de resistência ao caruncho Z. subfasciatus (Schoonhoven \& Cardona, 1982; Oriani et al., 1996). Contudo, em genótipos silvestres de $P$. vulgaris, de origem mexicana, detectaram-se altos níveis de resistência (Schoonhoven et al., 1983), e que a resistência deles aos carunchos é do tipo antibiose e é atribuída à proteína arcelina (Cardona et al., 1989). Seis variantes alélicas de arcelina (Arc1, Arc2, Arc3, Arc4, Arc5 e Arc6), que conferem diferentes graus de resistência, já foram descritas (Osborn et al., 1986; Lioi \& Bollini, 1989; Sparvoli \& Bollini, 1998).

O objetivo deste trabalho foi avaliar alternativas ao controle químico de Z. subfasciatus, em três genótipos de $P$. vulgaris.

\section{Material e Métodos}

O trabalho foi realizado no laboratório de Entomologia da Embrapa-Centro Nacional de Pesquisa de Arroz e Feijão (CNPAF), no Município de Santo Antônio de Goiás, $\mathrm{GO}$, em condições de temperatura e umidade não controladas. A temperatura ambiente e a umidade relativa foram registradas diariamente em termoigrógrafo.

O experimento foi conduzido em fatorial $3 \times 7 \times 10$, em delineamento inteiramente ao acaso, com quatro repetições, sendo o primeiro fator os genótipos (linhagens contendo os alelos arcelina 1 (Arc1) e arcelina 3 (Arc3), e a cultivar Carioca); o segundo, os tratamentos propriamente ditos e o terceiro, as épocas de amostragem. Os tratamentos consistiram da mistura aos grãos armazenados de óleo comercial comestível de soja ( $5 \mathrm{~mL} / \mathrm{kg}$ de grãos), óleo de nim ( $3 \mathrm{~mL} / \mathrm{kg}$ de grãos), munha (resíduos de trilha da colheita) (20 g/kg de grãos), calcário dolomítico ( $250 \mathrm{~g} / \mathrm{kg}$ de grãos), terra solta de formigueiro ( $250 \mathrm{~g} / \mathrm{kg}$ de grãos), inseticida malathion $500 \mathrm{CE}(40 \mathrm{~mL}$ p.c. $/ 500 \mathrm{~mL}$ água/tonelada grãos) e a testemunha (grãos não tratados). As amostragens foram realizadas a cada 15 dias, até os 150 dias após o início da armazenagem.

As linhagens Arc1 e Arc3 foram originalmente obtidas na Universidade de Wisconsin, Madison, EUA, pelo cruzamento da cultivar Porrillo 70 com acessos silvestres de P. vulgaris. As sementes dos genótipos testados foram multiplicadas no campo da Embrapa-CNPAF. Antes do tratamento, as sementes foram previamente selecionadas, descartando-se as que apresentavam imperfeições no tegumento, e as selecionadas foram mantidas, no mínimo, por 72 horas em condições ambiente, para entrar em equilíbrio higroscópico.

A unidade experimental para o armazenamento das sementes foi constituída de saco de algodão contendo $100 \mathrm{~g}$ 
de sementes. Cada unidade experimental, após o tratamento das sementes, foi infestada artificialmente com 10 casais de Z. subfasciatus, com até 24 horas após a emergência. Os insetos utilizados no experimento foram obtidos de uma colônia de laboratório mantida na Embrapa-CNPAF e multiplicados em sementes de feijão $P$. vulgaris, cultivar Jalo EEP 558.

O óleo de nim foi obtido da Embrapa-CNPAF, e preparado por meio da prensagem das sementes. A impregnação das sementes de feijoeiro com os óleos foi feita em saco de plástico, com agitação manual, por cerca de dois minutos, antes de as sementes serem colocadas no saco de algodão. Utilizou-se um saco de plástico para cada repetição, a fim de que não houvesse acúmulo do óleo, nas repetições posteriormente tratadas. O calcário e a terra de formigueiro passaram por uma peneira de malha de $0,3 \mathrm{~mm}$ e, assim como a munha e o inseticida, foram misturados aos grãos, nos sacos de algodão.

Em cada época de amostragem, foram retiradas 25 sementes de cada genótipo por repetição, para avaliação do número de ovos, número de adultos emergidos e porcentagem de sementes danificadas pelos carunchos. Para evitar que a quantidade de sementes fosse reduzida a cada período de amostragem - o que interferiria no substrato alimentar disponível aos carunchos -, cada repetição foi composta de dez sacos de sementes, numerados seqüencialmente de 1 a 10, de tal modo que cada unidade foi amostrada apenas uma vez. Após a contagem dos ovos, as sementes foram colocadas nos frascos, para verificação do número de adultos emergidos. Uma vez iniciada a emergência, os insetos foram contados a cada dois dias e retirados dos frascos. Após a emergência total, determinou-se a porcentagem de sementes danificadas, pela fórmula: $X=100 \mathrm{n} / \mathrm{N}$, em que n é o número de sementes danificadas e $\mathrm{N}$, o número total de sementes da amostra.

$\mathrm{Na}$ análise de variância, os dados referentes ao número de ovos e de adultos emergidos foram transformados em $(\mathrm{x}+1)^{0,5}$, e as porcentagens de sementes danificadas, em arco seno $(\mathrm{x} / 100)^{0,5}$. As médias foram comparadas pelo teste de Tukey, a $5 \%$ de probabilidade.

\section{Resultados e Discussão}

A temperatura média diária, durante a execução do experimento, variou de $16,6^{\circ} \mathrm{C}$ a $30,4^{\circ} \mathrm{C}$ e a umidade relativa de $55 \%$ a $86 \%$.

A linhagem Arc1 apresentou menor número de ovos $(32,89)$, de adultos emergidos $(4,34)$, e porcentagem de sementes danificadas (14,30\%). Em Arc3 constatou-se menor número de ovos $(160,17)$, comparativamente à cv. Carioca $(245,27)$; todavia, não houve diferença no número de adultos emergidos e na porcentagem de sementes danificadas (Tabela 1). Menor número de ovos e de adultos emergidos, de Z. subfasciatus, em linhagem derivada da variante de arcelina 1, em relação a arcelina 3, foram relatados por Cardona et al. (1990), Lara (1997), Barbosa et al. (1999, 2000).

O número de ovos foi menor em relação à testemunha, quando as sementes foram tratadas com malathion $(0,50)$, óleo de nim $(24,5)$, óleo de soja $(64,79)$ e terra de formigueiro $(140,45)$. Contudo, quando as sementes foram misturadas com a munha $(310,84)$, constatou-se maior número de ovos do que na testemunha $(221,92)$, ao passo que com o calcário $(259,78)$ não houve diferença significativa. Os menores números de adultos emergidos foram observados quando se utilizaram malathion $(0,008)$, óleo de nim $(3,62)$ e óleo de soja $(11,85)$. Os tratamentos com terra de formigueiro $(31,35)$, calcário $(37,76)$ e munha $(37,60)$ não diferiram da testemunha $(32,45)$ (Tabela 2$)$. A porcentagem de sementes danificadas pelos carunchos foi menor quando

Tabela 1. Número médio de ovos e de adultos emergidos e porcentagem média de sementes danificadas por Zabrotes subfasciatus em 25 sementes de três genótipos de feijão (Phaseolus vulgaris), no período de 150 dias de armazenagem $^{(1)}$.

\begin{tabular}{lccc}
\hline Genótipo & $\begin{array}{c}\text { Ovos } \\
\left(\mathrm{n}^{\mathrm{o}}\right)\end{array}$ & $\begin{array}{c}\text { Adultos } \\
\text { emergidos }\left(\mathrm{n}^{\mathrm{o}}\right)\end{array}$ & $\begin{array}{c}\text { Sementes } \\
\text { danificadas }(\%)\end{array}$ \\
\hline Carioca & $245,27 \mathrm{a}$ & $32,11 \mathrm{a}$ & $47,70 \mathrm{a}$ \\
Arc3 & $160,17 \mathrm{~b}$ & $29,82 \mathrm{a}$ & $42,63 \mathrm{a}$ \\
Arc1 & $32,89 \mathrm{c}$ & $4,34 \mathrm{~b}$ & $14,30 \mathrm{~b}$ \\
\hline
\end{tabular}

(1)Médias seguidas da mesma letra na coluna não diferem entre si pelo teste de Tukey, a 5\% de probabilidade. Dados não transformados.

Tabela 2. Número médio de ovos e de adultos emergidos e porcentagem média de sementes danificadas por Zabrotes subfasciatus em 25 sementes de três genótipos de feijão (Phaseolus vulgaris), em diferentes tratamentos, no período de 150 dias de $\operatorname{armazenagem}^{(1)}$.

\begin{tabular}{lccc}
\hline Tratamento & $\begin{array}{c}\text { Ovos } \\
\left(\mathrm{n}^{-}\right)\end{array}$ & $\begin{array}{c}\text { Adultos } \\
\text { emergidos }\left(\mathrm{n}^{\mathrm{o}}\right)\end{array}$ & $\begin{array}{c}\text { Sementes } \\
\text { danificadas }(\%)\end{array}$ \\
\hline Munha & $310,84 \mathrm{a}$ & $37,60 \mathrm{a}$ & $62,93 \mathrm{a}$ \\
Testemunha & $221,92 \mathrm{~b}$ & $32,45 \mathrm{ab}$ & $59,17 \mathrm{a}$ \\
Calcário & $259,78 \mathrm{~b}$ & $37,76 \mathrm{a}$ & $58,57 \mathrm{a}$ \\
Terra de formigueiro & $140,45 \mathrm{c}$ & $31,35 \mathrm{~b}$ & $38,70 \mathrm{~b}$ \\
Óleo de soja & $64,79 \mathrm{~d}$ & $11,85 \mathrm{c}$ & $18,77 \mathrm{c}$ \\
Óleo de nim & $24,50 \mathrm{e}$ & $3,62 \mathrm{~d}$ & $5,17 \mathrm{~d}$ \\
Malathion & $0,50 \mathrm{f}$ & $0,08 \mathrm{e}$ & $0,83 \mathrm{~d}$ \\
\hline
\end{tabular}

(1)Médias seguidas da mesma letra na coluna não diferem entre si pelo teste de Tukey, a $5 \%$ de probabilidade. Dados não transformados. 
estas foram tratadas com malathion $(0,83 \%)$, óleo de $\operatorname{nim}(5,17 \%)$, óleo de soja $(18,77 \%)$, ou com terra de formigueiro $(38,70)$. Não houve diferença significativa entre o tratamento com o óleo de nim e o malathion, o que indica o alto nível de proteção ao ataque de Z. subfasciatus, pelo óleo de nim, mesmo quando comparado ao inseticida químico. Os tratamentos com calcário $(58,57 \%)$ e munha $(62,93 \%)$ não diferiram da porcentagem de sementes danificadas da testemunha $(59,17 \%)$ (Tabela 2). Hall \& Harman (1991) também constataram que o tratamento de sementes armazenadas de $P$. vulgaris com óleo de soja resultou em redução da oviposição, da emergência de adultos e dos danos de Z. subfasciatus. Com relação ao calcário dolomítico, após quatro meses de armazenamento do caupi, Barreto et al. (1983) observaram redução da população do caruncho A. obtectus. Tais resultados diferem dos obtidos no presente trabalho, $\operatorname{com} Z$. subfasciatus.

No período de 15 a 150 dias de armazenagem, os números médios de ovos e de adultos emergidos variaram, respectivamente, de 9,46 a 355,93 e de 5,06 a 40,58, enquanto a porcentagem de sementes danificadas variou de 9,85 a 57,95\% (Tabela 3). Até os 45 dias de armazenagem, não houve diferença no número de ovos e de adultos emergidos. Não se observou também diferença no número de ovos entre 45 e 60 dias, 90 e 105 dias e 135 a 150 dias de armazenagem, assim como não se constataram diferenças significativas no número de adultos dos 60 aos 150 dias. Em relação à porcentagem de sementes

Tabela 3. Número médio de ovos e de adultos emergidos e porcentagem média de sementes danificadas por Zabrotes subfasciatus em 25 sementes de três genótipos de feijão (Phaseolus vulgaris), em diferentes períodos de armazenagem $^{(1)}$.

\begin{tabular}{cccc}
\hline $\begin{array}{c}\text { Amostragem } \\
(\text { dias })\end{array}$ & $\begin{array}{c}\text { Ovos } \\
\left(\mathrm{n}^{\mathrm{o}}\right)\end{array}$ & $\begin{array}{c}\text { Adultos } \\
\text { emergidos }\left(\mathrm{n}^{\mathrm{o}}\right)\end{array}$ & $\begin{array}{c}\text { Sementes } \\
\text { danificadas }(\%)\end{array}$ \\
\hline 15 & $10,88 \mathrm{f}$ & $5,06 \mathrm{c}$ & $9,85 \mathrm{~g}$ \\
30 & $9,46 \mathrm{f}$ & $5,44 \mathrm{c}$ & $12,09 \mathrm{fg}$ \\
45 & $24,76 \mathrm{ef}$ & $12,82 \mathrm{c}$ & $17,52 \mathrm{f}$ \\
60 & $41,54 \mathrm{e}$ & $27,65 \mathrm{ab}$ & $28,85 \mathrm{e}$ \\
75 & $111,39 \mathrm{~d}$ & $40,58 \mathrm{a}$ & $36,42 \mathrm{~d}$ \\
90 & $147,52 \mathrm{c}$ & $28,76 \mathrm{ab}$ & $38,71 \mathrm{~cd}$ \\
105 & $188,81 \mathrm{c}$ & $28,18 \mathrm{ab}$ & $43,57 \mathrm{bc}$ \\
120 & $237,19 \mathrm{~b}$ & $26,79 \mathrm{ab}$ & $48,28 \mathrm{~b}$ \\
135 & $333,62 \mathrm{a}$ & $22,83 \mathrm{~b}$ & $55,47 \mathrm{a}$ \\
150 & $355,93 \mathrm{a}$ & $22,81 \mathrm{~b}$ & $57,95 \mathrm{a}$ \\
\hline
\end{tabular}

(1)Médias seguidas da mesma letra na coluna não diferem entre si pelo teste de Tukey, a 5\% de probabilidade. Dados não transformados. danificadas não houve diferença entre 15 e 30 dias, 30 e 45 dias, 75 e 90 dias, 90 e 105 dias, 105 e 120 dias, nem entre 135 e 150 dias.

\section{Conclusões}

1. A linhagem portadora do alelo arcelina 1 (Arc1) apresenta maior proteção aos danos do caruncho Z. subfasciatus do que a linhagem Arc3 e a cultivar Carioca.

2. Até 150 dias de armazenagem, alto nível de proteção aos danos de Z. subfasciatus pode ser conseguido pelo tratamento das sementes com o óleo de nim e de soja.

3. O tratamento das sementes com óleo de nim ou com malathion proporciona igual proteção contra os danos causados por Z. subfasciatus.

4. A mistura das sementes com terra de formigueiro, ou com munha ou com calcário dolomítico não confere proteção contra os danos do caruncho.

\section{Referências}

BARBOSA, F. R.; YOKOYAMA, M.; PEREIRA, P. A. A.; ZIMMERMANN, F. J. P. Danos de Zabrotes subfasciatus (Boh.) (Coleoptera: Bruchidae) em linhagens de feijoeiro (Phaseolus vulgaris L.). Anais da Sociedade Entomológica do Brasil, Londrina, v. 29, n. 1, p. 113121, 2000.

BARBOSA, F. R.; YOKOYAMA, M.; PEREIRA, P. A. A.; ZIMMERMANN, F. J. P. Efeito da proteína arcelina na biologia de Zabrotes subfasciatus (Boheman 1833) em feijoeiro. Pesquisa Agropecuária Brasileira, Brasília, v. 34, n. 10, p. 1805-1810, out. 1999.

BARRETO, B. A.; BERTOLDO, N. G.; CAETANO, W. Efeitos de inseticidas, material inerte e óleo comestível no controle do caruncho do feijão. Jornal da Armazenagem, Brasília, v. 4, n. 16, p. 6-7, 1983.

CARDONA, C.; KORNEGAY, J.; POSSO, C. E; MORALES, F.; RAMIREZ, H. Comparative value of four arcelin variants in the development of dry bean lines resistant to the Mexican bean weevil. Entomologia Experimentalis et Applicata, Dordrecht, v. 56, p. 197 206, 1990.

CARDONA, C.; POSSO, C. E.; KORNEGAY, J.; VALOR, J.; SERRANO, M. Antibiosis effects of wild dry bean accessions on the Mexican bean weevil and the bean weevil (Coleoptera:Bruchidae). Journal of Economic Entomology, Lanham, v. 82, n. 1, p. 310-315, 1989. 
DON-PEDRO, K. N. Mode of action of fixed oils against eggs of Callosobruchus maculatus (F>). Pesticide Science, Lanham, v. 26, n. 2, p. 107-116, 1989.

GALLO, D.; NAKANO, O.; SILVEIRA NETO, S.; CARVALHO, R. P. L.; BATISTA, G. C.; BERTI FILHO, E.; PARRA, J. R. P.; ZUCCHI, R. A.; ALVES, S. B.; VENDRAMIM, J. D. Manual de entomologia agrícola. 2. ed. São Paulo: Agronômica Ceres, 1988. 649 p.

GUEDES, R. N. C. Manejo integrado para a proteção de grãos armazenados contra insetos. Revista Brasileira de Armazenamento, Viçosa, MG, v. 15/16, n. 1/2, p. 3-47, 1991.

GUTIERREZ, B. A. de; SCHOONHOVEN, A. van. Proteja su cosecha de fríjol contra el ataque de los gorgojos. Palmira: Instituto Colombiano Agropecuario, 1981. 12 p. (Boletín Divulgativo, 66).

HALL, J. S.; HARMAN, G. E. Efficacy of oil treatments of legume seeds for control of Aspergillus and Zabrotes. Crop Protection, Oxford, v. 10, p. 315-319, 1991.

LARA, F. M. Resistance of wild and near isogenic bean lines with variants to Zabrotes subfasciatus (Boheman). I. Winter crop. Anais da Sociedade Entomológica do Brasil, Londrina, v. 26, n. 3, p. 551-560, 1997.

LIOI, L.; BOLLINI, R. Identification a new arcelin variant in wild bean seeds. Annual Report of the Bean Improvement Cooperative, East Lansing, v. 32, p. 28, 1989.

MORDUE, A. J. M.; NISBET, A. J. Azadirachtin from the neem tree Azadirachta indica: its actions against insects. Anais da Sociedade Entomológica do Brasil, Londrina, v. 29 , n. 4 , p. $615-632,2000$.

OLIVEIRA, J. V.; VENDRAMIM, J. D. Repelência de óleos essenciais e pós vegetais sobre adultos de Zabrotes subfasciatus (Boh.) (Coleoptera: Bruchidae) em sementes de feijoeiro. Anais da Sociedade Entomológica do Brasil, Londrina, v. 28, n. 3, p. 549-555, 1999.

ORIANI, M. A. de G.; LARA, F. M.; BOIÇA JUNIOR, A. L. Resistência de genótipos de feijoeiro a Zabrotes subfasciatus (Boh.) (Coleoptera:Bruchidae). Anais da Sociedade Entomológica do Brasil, Londrina, v. 25, n. 2, p. 213-216, 1996.

OSBORN, T. C.; BLAKE, T.; GEPTS, P.; BLISS, F. A. Bean arcelin, 2: genetic variation, inheritance and linkage relationships of a novel seed protein of Phaseolus vulgaris L. Theoretical and Applied Genetics, Berlin, v. 71, n. 6, p. $847-855,1986$.

SCHOONHOVEN, A. van; CARDONA, C. Low levels of resistance to the Mexican bean weevil in dry bean. Journal of Economic Entomology, Lanham, v. 76, n. 4, p. 567-569, 1982.

SCHOONHOVEN, A. van; CARDONA, C.; VALOR, J. Resistance to the bean weevil and the Mexican bean weevil (Coleoptera: Bruchidae) in noncultivated common bean accessions. Journal of Economic Entomology, Lanham, v. 76, n. 6, p. 1255-1259, 1983.

SPARVOLI, F.; BOLLINI, R. Arcelin in wild bean (Phaseolus vulgaris L.) seeds: sequence of arcelin 6 shows it is a member of the arcelins 1 and 2 subfamily. Genetic Resources and Crop Evolution, Dordrecht, v. 45, n. 4, p. 383-388, 1998.

TOLEDO, F. F. de; MARCOS FILHO, J. Manual das sementes: tecnologia da produção. São Paulo: Agronômica Ceres, 1977. 244 p.

UVAH, I. I.; ISHAYA, A. T. Effect of some vegetable oils on emergence, oviposition and longevity of the bean weevil, Callosobruchus maculatus (F.). Tropical Pest Management, Lanham, v. 38, n. 3, p. 257-260, 1992. 